\title{
AS MAÇÃS DO PARAÍSO ADÂMICO: CLARICE LISPECTOR E AS ARTES POÉTICAS DE SOPHIA DE MELLO BREYNER
}

\author{
Fernanda Drummond ${ }^{1}$
}

RESUMO: As literaturas de Clarice Lispector e Sophia de Mello Breyner Andresen atentam para o primordial e se perguntam, numa autorreflexão, pela origem e pela nomeação. A partir do romance $A$ maşã no escuro, da primeira, e do texto "Arte Poética III", da segunda, tecemos algumas considerações que as vinculam à antiguidade clássica.

PALAVRAS-CHAVE: Clarice Lispector; Mito da Caverna; Nomeação; Sophia de Mello Breyner Andresen.

\section{APPLES IN THE ADAMIC PARADISE: WORKS OF CLARICE LISPECTOR AND SOPHIA DE MELLO BREYNER ANDRESEN'S ARS POETICAE}

\begin{abstract}
The literary works of Clarice Lispector and Sophia de Mello Breyner Andresen are attentive to the primordial understanding thought and forces, and they metaliguistically pose questions about the origins and naming. From the novel The apple in the dark, by the first, and the prose work "Arte Poética III", by the latter, some thoughts are coined with efforts to link the two writers to classical antiquity.
\end{abstract}

KEYWORDS: Clarice Lispector; Plato's Cave; Naming; Sophia de Mello Breyner Andresen.

1 Mestranda em Literatura Portuguesa pela UFRJ/Bolsista CAPES. 
Ninguém jamais escreveu ou pintou, esculpiu, modelou ou inventou senão para sair do inferno.

(Antonin Artaud)

O romance $A$ maşã no escuro, de Clarice Lispector, foi escrito durante os anos de isolamento da escritora nos Estados Unidos, enquanto acompanhava o seu marido em carreira diplomática. O biógrafo Benjamin Moser aponta que o livro foi "iniciado em Torquay e escrito em sua pacata sala de estar em Chevy Chase", onde Clarice lutava continuamente com "a depressão e o desespero no exílio” (MOSER, 2011, p. 377, 410). Talvez por isso ele se configure como um romance árduo, que mimetize um rompimento com a linguagem. Ou melhor, o romance encara, como Lispector sempre fez, a face do indizível engendrado na comunicação humana. É ainda no terreno da língua, espaço mais restrito que a linguagem, que o conflito se dá.

Martim, o protagonista desse drama, foge da cidade em direção ao descampado, escapando de um possível crime: teria, supostamente matado a sua esposa. Vivendo, graças ao autoexílio, numa esfera amoral, acontece a ele reconfigurar-se. Enquanto se afasta das leis humanas, vai progressivamente se destituindo de sua capacidade de comunicação em sociedade, de sua personalidade, identidade, até se tornar o puro neutro, "apenas ele mesmo", ou: "o gosto que a língua tem na própria boca” (LISPECTOR, 1998, p. 32).

É nessa coincidência concêntrica entre duas coisas que foram feitas para residir uma dentro da outra - língua e boca - que a pesquisa de linguagem de Clarice acontece. Esse reencontro com o neutro corresponde à necessidade expressa na primeira parte do romance. "Como se faz um homem" é o título da referida seção, na qual se procura a coincidência primordial entre nome e coisa: "como um ponto desenhado sobre o mesmo ponto, a voz do grilo era o próprio grilo, e nada informava" (id., p. 14) - eis a sobreposição de voz e corpo, para a qual a mensagem mal importa, como também não importa a informação veiculada pela voz emitida pelo corpo. O que é crucial é a unidade entre o que se mostra de um ser e o que ele 
é em verdade.

Mas é apenas na claridade que se pode vislumbrar essa coincidência ontológica. De resto, tudo parecerá com uma eterna diferença entre ser e ente. Os gregos festejaram, na valorização dos olhos, o sobrepujo dessa luminosidade que tudo alcançava. Tal confiança na luz que revela as coisas está figurada em Sophia de Mello Breyner Andresen, poetisa que deve à antiguidade clássica o manifesto entusiasmo pela inteireza. Em "Arte Poética III", texto em prosa no qual explicita algumas razões de sua escrita, a poetisa diz:

A coisa mais antiga de que me lembro é dum quarto em frente do mar dentro do qual estava, poisada em cima duma mesa, uma maçã enorme e vermelha. Do brilho do mar e do vermelho da maçã erguia-se uma felicidade irrecusável, nua e inteira. Não era nada de fantástico, não era nada de imaginário: era a própria presença do real que eu descobria. [...] Em Homero reconheci essa felicidade nua e inteira, esse esplendor da presença das coisas. (ANDRESEN, 2010, p. 841)

Acontece que nem sempre a presença das coisas se evidencia em um ambiente claro (embora o verbo “evidenciar" aponte para nidere, ver). Para desafogar a visão da obrigatoriedade que teria de nos conduzir, Clarice Lispector desenvolve o motivo do seu título:

Porque entender, aliás, é uma atitude. Como se agora, estendendo a mão no escuro e pegando uma maçã, ele reconhecesse nos dedos tão desajeitados pelo amor uma maçã. Martim já não pedia mais o nome das coisas. Bastava-lhe reconhecê-las no escuro. E rejubilar-se, desajeitado.

E depois? Depois, quando saísse para a claridade, veria as coisas pressentidas com a mão, e veria essas coisas com seus falsos nomes.

(LISPECTOR, 1998, pp. 295-296)

É o sentido do tato que é aqui valorizado - porém o alcance, o estender da mão, se deve à disposição da maçã no escuro. Comparando-se as duas últimas citações, entendemos a diferença entre uma fruta ser intuída e evidenciada pela luz enquanto a outra - a maçã de Clarice - é percebida pela escuridão. São esses dois modos de presença que se fazem valer: escuridão e claridade são a garantia do real mesmo que não possamos apontá-lo. A intuição que a racionalidade projeta não exclui a possibilidade de estarmos enganados quando vemos as coisas em plena luz, bem como o tatear no escuro não invalida o pressentimento. O poeta nutre a capacidade de apontar, mesmo sem ver, aquilo que existe, sem depender do fato de os 
objetos estarem à mostra e passarem pelos olhos. Há quem "sintonize" o real a partir da audição, como a poetisa canadense Anne Carson: "Reality is a sound, you have to tune in to it not just keep yelling" (CARSON, 1998, p. 60) ${ }^{2}$.

É quase impossível não vermos na saída "para a claridade", de Lispector, uma evocação do mito da caverna, de Platão: "os olhos não podem passar das trevas para a luz sem que todo o corpo se volte nessa direção" (PLATÃO, [s/d], p. 292), assim como os sentidos de Martim têm que, primeiro, harmonizar-se com o pressentido: "embora no fundo do sono alguma coisa ecoasse difícil, tentando se organizar” (LISPECTOR, 1998, p. 14). Segundo Ronaldes de Melo e Souza, na alegoria da caverna "a verdade é descrita e circunscrita pela visibilidade ou pelo modo como as coisas se evidenciam, segundo um foco que as mostra sob determinada forma" (SOUZA, 2001, [s/p]). No texto clariciano, a evidência não depende do desvelamento de que participa a visão e a claridade, já que uma vez do lado de fora, "as coisas pressentidas com a mão" têm atribuídas a si um falso nome. Dessa forma, de nada adiantaria o cavernícolo iluminado, liberto das trevas, resgatar seus con-cidadãos da caverna, uma vez que a nomeação não pretende obedecer ao modo com que o real se dá a ver.

De outra maneira sintonizada aos processos de nomear, Sophia de Mello Breyner confere à palavra um poder de realização, de modo a trazer as coisas à presença, por meio do lógos. É isso que acreditamos estar no cerne de poemas como "Lisboa", que inaugura o volume Navegaçôes:
Digo:
"Lisboa"
Quando atravesso - vinda do sul - o rio
$\mathrm{E}$ a cidade a que chego abre-se como se do meu nome nascesse
(ANDRESEN, 2010, p. 667)

Parece-nos, então, que o ato poético andreseniano está na confiança de a palavra inaugurar um real, qual seja: a abertura de uma cidade diante dos olhos. É, dito de outra forma, a reivenção da fórmula bíblica "No princípio era o verbo". Do verbo, graças à palavra poética, nasce uma cidade, como depois nasce Adão a partir do barro.

A nomeação adâmica, de acordo com Walter Benjamin, remonta à capacidade de

2 “A realidade é um som, você tem que se sintonizar a ela, não só continuar gritando.” [versão nossa] 
apontar o que há e vincular isto a um nome. Para ele, essa ação é recuperada pelo filósofo, mas no germe dessa iniciativa não está Platão, mas sim Adão: "na contemplação filosófica, (...) a palavra reinvindica seus direitos de nomeação" (BENJAMIN, 1985, p. 59). Em literatura, conquanto a procura da nomeação mais justa (lembrar da mot juste de Flaubert), temos visões multiformes do conhecimento, do acontecer e da verdade. Enquanto em Platão a verdade é logocêntrica e discursiva - ligada à didática de alguém que se dispõe a tirar os seres da ignorância -, em Adão a alétheia é inaugural, está de acordo com a vivência do acontecimento. Por isso, para Sophia, a obra poética não faz parte de uma "cultura" em que se "transmitem conhecimentos" - tal como na paideia da caverna platônica - mas é o lugar onde o real tem espaço para florescer: "Dizer que a obra de arte faz parte da cultura é uma coisa um pouco escolar e artificial. A obra de arte faz parte do real e é destino, realização, salvação e vida" (ANDRESEN, 2010, p. 841).

No percurso de Martim, de A maçã no escuro, desde seu nascimento recriado, a partir do estado de silêncio, sem fala, até a liberdade de ver as coisas inteiramente do lado de fora, "na claridade", o personagem empreende uma aprendizagem que não descarta o tatear, o "modo instável de pegar no escuro uma maçã" (LISPECTOR, 1998, p. 334). O desejo de apreender, ou de reter, também se mostra fulcral tanto na escrita de Lispector como na Andresen. É para fixar o objeto no instante - para não deixar a maçã cair, ou para impedi-la de desaparecer - que as autoras se aventuram na criação. Diz Sophia de Mello Breyner: "Sempre a poesia foi para mim uma perseguição do real. Um poema foi sempre um círculo traçado à roda duma coisa, um círculo onde o pássaro do real fica preso” (ANDRESEN, 2010, p. 841).

Portanto, apreende-se que é a partir deste fato que passa a caber ao poeta

Transferir o quadro o muro a brisa

A flor o copo o brilho da madeira

E a fria e virgem liquidez da água

Para o mundo do poema limpo e rigoroso

Preservar de decadência morte e ruína

O instante real de aparição e de surpresa

Guardar num mundo claro

O gesto claro da mão tocando a mesa

(ANDRESEN, 2010, p. 405) 
O poema passa a ser, neste exemplo do Livro Sexto, o lugar - mais uma vez - "claro", em que se guardam gestos seguros, distantes da dúvida. Em "A Forma Justa”, em vez de adequar a poética à correção do olhar, a poetisa logra "constuir a forma justa/ De uma cidade humana que fosse/ Fiel à perfeição do universo// Por isso recomeço sem cessar a partir da página em branco/ E este é meu ofício de poeta para a reconstrução do mundo" (ANDRESEN, 2010, p. 660).

Preocupada com a preservação de um mundo claro em meio às ruínas, a poesia de Andresen se ocupa da visão do real a partir da iluminação justamente porque está inserida num mundo de desastres; assim diz "Tempo de não":

Exausta fujo as arenas no puro intolerável

Os deuses da destruição sentaram-se ao meu lado

A cidade onde habito é rica de desastres

Embora exista a praia lisa que sonhei (id., p. 715)

A confiança, por outro lado, tanto na "praia lisa", quanto no "mundo claro", preservado da morte e da ruína, concretiza a anábase do poeta a partir do inferno, em consonância com o que dizia Artaud, na nossa epígrafe. Além disso, passa-se a se confundir a ação da escrita com a criação do mundo. A partir do eterno recomeço da "página em branco" (Cf. "A forma justa"), também Martim tentará um "trabalho de construção da realidade" (LISPECTOR, 1998, p. 140):

A seu desfavor tinha um perigo à espreita: é que havia um gosto e uma beleza em uma pessoa se perder. A seu desfavor tinha ainda o fato de entender pouco. Mas sobretudo a seu favor tinha o fato de que não entender era o seu limpo ponto de partida.

(id. ibid.)

Há vantagens em não entender - Clarice costuma subverter o entendimento como faculdade do intelecto, deslocando-o para a sensação pré-linguistica. Daí a necessidade do silêncio para se perceber a presença e "pensar ou sentir", ou "pensar-sentir", essa reunião tão pessoana de que, no seu fluxo de consciência, Lispector não abre mão: “como se ele próprio se tivesse tornado grande demais e espalhado, e, por algum motivo que já esquecera, precisasse obscuramente se recolher para talvez pensar ou sentir" (LISPECTOR, 1998, p. 16). "Pensar" ou "sentir", no entanto, são atos vinculados à vida antiga de Martim, hábitos que estavam 
ligados à inteligibilidade de que necessitava na convivência social. Por isso, durante sua fuga e “(re)descoberta do mundo", ele apenas julga que precisa se afastar da vida para "pensar" e "sentir" questões recônditas, "por algum motivo que já esquecera". O reforço da inteligibilidade do sensível deixa reminiscências no comportamento do protagonista de $A$ maçã no escuro.

Os personagens claricianos, não raro, precisam passar pelo estágio de não entender para passar a intuir e depois - último estágio - saber: "Então as coisas passaram a se reorganizar a partir dele próprio: trevas foram sendo entendidas, ramos começaram lentamente a se formar sob o balcão, sombras se dividiram em flores ainda irresolutas" (LISPECTOR, 1998, pp. 16-17). Nesse interstício de névoa, a autora brasileira recria o momento da gênese. Jean-Pierre Vernant localiza em diversas teogonias - inclusive na que inspirará a mitologia bíblica - o pensamento em que "na origem", afirma ele, é posto "um estado de indistinção em que nada ainda aparece. [...] Desta unidade primordial emergem, por segregação e diferenciação progressivas, pares de opostos [...]” (VERNANT, 2004, pp. 112-113).

É no caminho do não-ser para a cosmogonia do ser, a partir da intuição para a descoberta, que chegamos ao final evocando a origem: se "no princípio era o verbo", e as palavras ditas eram "faça-se a luz", assim pôde se separar o dia a partir da noite. Da mesma maneira podemos agora evocar a imagem do fruto proibido, que expulsa Adão e Eva dos jardins do paraíso. A maçã é, na Bíblia, a fruta que "constitui por si só uma promessa de mundo, um convite a estar no mundo" (BACHELARD, 1988, p. 168). O fruto do desejo, havendo ou não luz, pede que o alcancem - e, estendendo a mão, o homem cria uma lacuna entre ele mesmo e o seu objeto de ruína. Sendo assim, seu paraíso pré-linguístico é substituído pela necessidade de atribuir um nome e um juízo a cada coisa que se lhe revela.

A imagem da maçã continua a reverberar, porque, como símbolo de volição, ela passa a ser, no Cântico dos Cânticos, a concretização do amor na prenda entre dois amantes:

Como a maçã entre as madeiras do arvoredo

Assim, entre outros filhos, vem a ser

O meu amado.

$[\ldots]$

Com bolos de mel me recupera, 
E com maçãs me reanima

Que eu ferida estou dos teus encantos.

(SALOMÃO, 2008, p. 53)

Em Safo de Lesbos, no fragmento 105 a, o fruto aparece mais uma vez inatingível, embora sua vermelhidão a torne mais madura e acentue sua realidade:

as the sweetapple reddens on a high branch high on the highest branch and the applepickers forgot no, not forgot: were unable to reach

(SAPPHO, 2003, pp. 214-215) ${ }^{3}$

Afinal podemos intuir que as maçãs têm composto metáforas da falta. Em Safo o fruto “proibido" está à mostra, embora seja inalcançável, não obstantes os esforços. Nessa falta pode repousar a promessa de um mundo justo - correspondente à inteireza que se ergue do real ou também pode estar recôndita a resposta para a interdição do sentido da visão - como em $A$ maçã no escuro.

A literatura de Clarice Lispector, ao compor um crime sem castigo, propõe outra vez a caminhada em direção à origem, além de aludir ao ato de criação do Velho Testamento. De acordo com Benjamin Moser, com suas "referências a maçãs, crimes e quedas", o romance "é obviamente uma alegoria da criação, e uma alegoria da criação por meio da palavra" (MOSER, 2011, p. 387). Entretanto, nesse recuo, ao invés de um “começo sem verbo", a palavra opera uma salvação: a redenção dos pecados a partir da desconstrução da língua e dos aparatos que engessam os homens. Esta salvação, diz-nos Deleuze, "eles não a esperam mais da profundidade da terra ou da autoctonia, muito menos do céu e da Ideia, eles a esperam lateralmente do acontecimento"4 - no qual as epifanias terão um papel decisivo.

No afã de preservar da decadência e da ruína a inteireza apreendida de início, "como Antígona a poesia do nosso tempo diz: 'Eu sou aquela que não aprendeu a ceder aos desastres"” (Andresen, 2010, p. 842). Como está claro que Sophia buscará na Grécia os seus interlocutores preferidos, recuperamos Safo e o Velho Testamento para dialogar com seus poemas. Dessa forma, a cena andreseniana da maçã vermelha sobre a mesa parecerá a nós mais

3 “enquanto a doce maçã avermelha num galho alto/ lá em cima no galho mais alto que os colhedores esqueceram - / não, não esqueceram: não conseguiram alcançar” [versão nossa]

4 In: DELEUZE, 2006, p. 133. 
do que uma lembrança antiga: será, antes, uma reminiscência do primordial.

\section{Referências Bibliográficas}

ANDRESEN, Sophia de Mello Breyner. Obra Poética. Lisboa: Caminho, 2010.

BACHELARD, Gaston. A poética do devaneio. Trad. Antonio de Pádua Danesi. São Paulo: Martins Fontes, 1988.

BENJAMIN, Walter. A origem do drama barroco alemão. Trad. Sérgio Paulo Rouanet. São Paulo: Ed. Brasiliense, 1985.

CARSON, Anne. Autobiography of red. New York: Vintage, 1998.

DELEUZE, Gilles. Lógica do sentido. Trad. Luiz Roberto Salinas Fortes. São Paulo: 2006.

LISPECTOR, Clarice. A maşã no escuro. Rio de Janeiro: Rocco, 1998.

MOSER, Benjamin. Clarice, uma biografia. Trad. José Geraldo Couto. São Paulo: Cosac Naify, 2011.

PLATÃO. A República. Trad. Albertino Pinheiro. São Paulo: Atena Editora, [s/d], $\sigma^{a}$ edição.

SALOMÃO. Cântico dos cânticos. Trad. Antonio Medina Rodrigues. São Paulo: Hedra, 2008.

SAPPHO. If not, winter. Trad. para o inglês Anne Carson. Toronto: Vintage Canada, 2003.

SOUZA, Ronaldes de Melo e. "A Desconstrução da metafísica e a reconciliação de poetas e filósofos". Internet: http://www.litcult.net/revistalitcult_vol1.php?id=13, 2001 (acesso em 01-02-2012).

VERNANT, Jean-Pierre. As origens do pensamento grego. Trad. Ísis Borges B. da Fonseca São Paulo: Difel, 2004. 